\title{
Management Hypotheses to Improve Yield-per-Recruit and Economic Returns in the Red Shrimp (Aristaemorpha foliacea) Fishery of Southern Sicily (Mediterranean Sea)
}

\author{
Marco L. Bianchini \\ Italian National Research Council (C.N.R.) and Società Porto Romano s.p.a. \\ Piazza Pasquale Paoli 3, 00188 Roma, Italy \\ and \\ Sergio Ragonese and Dino Levi \\ Ist. di ricerche sulle Risorse Marine e l'Ambiente, IRMA-C.N.R., Mazara, Italy
}

\begin{abstract}
The giant red shrimp, Aristaemorpha foliacea, is a deep-water benthopelagic shrimp, distributed in the Mediterranean, Eastern Atlantic, Western and Central Pacific; in the Strait of Sicily, the annual landings exceed 1000 tons, worth over US\$ 10 million. Two series of trawl experiments, carried out in 1985-87 and 1993 with different aims (trawl survey and selectivity study), produced two sets of data, which were used to reconstruct the length distribution of the landings and the life history of the stock (growth parameters, mortalities, size/age structure, etc.). Using the package ANALEN, and the estimated parameters, different short-term and long-term yield realizations are presented, both in terms of weight or value, when varying fishing mortality and/or mesh size (mesh size of reference, $40 \mathrm{~mm}$ stretched). Using the package VIT, the transitional evolution of the fishery, both in terms of biomass and of economic returns, is examined under three different management schemes: a sudden reduction of the fishing mortality of $15 \%$ or of $25 \%$, and a reduction of $35 \%$ in seven years $(5 \% / \mathrm{yr})$. In the transitional analyses, the older set shows a situation in which yields decrease and stay below the starting figure, following any reduction of the fishing mortality; examining the economic returns, after the initial decrease, the gross incomes stabilize more or less at the previous level. With the more recent set, in every studied management scheme, the yield bounces above the starting line already in the third year, with a stationary increase of $6-8 \%$; the higher the fishing mortality reduction, the higher the final economic equilibrium, respectively approx. $5 \%, 10 \%$ and $15 \%$ above the initial value after four years. Applying a stochastic variability of even modest intensity to the recruitment produces ample fluctuations of yield. In conclusion, despite the uncertainty of the models, the results seem to show that the red shrimp fishery situation has worsened from 1985 to 1993, and suggest that a reduction of effort/fishing mortality is biologically sound, has almost no influence on catches and is economically advantageous (or, at the worst, neutral).
\end{abstract}

Keywords: Aristaeomorpha foliacea, assessment, Central Mediterranean, fishery, giant red shrimp

\section{Introduction}

The giant red shrimp, Aristaemorpha foliacea, Risso 1827 is a deep-water benthopelagic shrimp, distributed in the Mediterranean, Eastern Atlantic, Western and Central Pacific (Bianchini and Ragonese, 1994). In the Strait of Sicily, the annual landings exceed 1000 tons, worth over US\$10 million.
In recent years, the life history of the populations in Italian waters has been extensively studied (full list of references in Relini et al., 1999). For the Sicilian stock, the biology (distribution, morphometry, maturity, mortality and growth) has been described (Ragonese et al., 1997; Ragonese and Bianchini, 1995; Ragonese et al., 1994), as well as some aspects (selectivity, enmeshing, technology, VPA, diel 
variation, by-catch) of the red shrimp fishery (Bianchini et al., 1998a; Ragonese et al., 2002; Ragonese et al., 2001; Bianchini and Ragonese, 2001; Bianchini et al., 1998b), but studies relevant to the management of this resource are still lacking.

This paper aims to provide a theoretical analysis of the evolution of the fishery and to evaluate shortterm and long-term effects, on the biomass and on the value of the catch, resulting from possible management interventions. The evolution of the transitional period has also been examined.

\section{Materials and Methods}

The shrimps, A. foliacea, were collected during two periods, 1985-87 and 1993 from the Strait of Sicily, in study areas which are shown in Fig. 1.

In the first period, red shrimp length-frequency distributions (LFDs) were derived from 8 seasonal trawl surveys (codend with square mesh, $32 \mathrm{~mm}$ stretched) conducted from Spring 1985 to Winter 1987 (Levi et al., 1998); 19600 females were measured (carapace length, $\mathrm{CL}, \mathrm{mm}$ ). In the second period, LFDs were from a covered-codends (cover, square mesh of $28 \mathrm{~mm}$ stretched; codend, square mesh of $40 \mathrm{~mm}$ stretched) selectivity study carried out in the Strait of Sicily in 1993 (Bianchini, 1999); the total female catch (84 000 animals) was measured without subsampling. Both sets of data cover the period when the very young and small shrimps are present. It must be noted that the population reconstruction results should be taken cautiously, since both data sets used come from experimental hauls, and are therefore only an approximation of the population structure of the

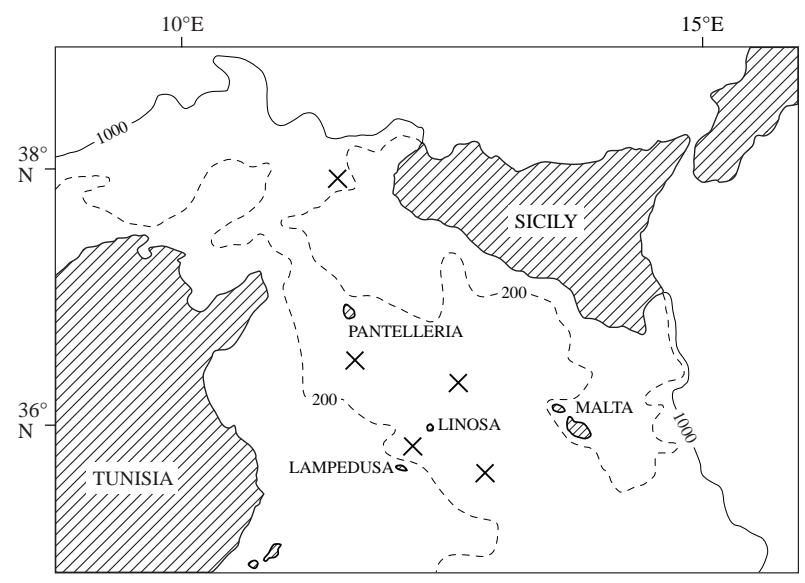

Fig. 1. The area of study, indicating the major fishing grounds. actual landings, and since the steady-state assumptions might not be fulfilled. Nevertheless, since in the red shrimp fishery of the Strait of Sicily captures and landings are almost coincident (there are no rejects, and selectivity is almost nil with the $40 \mathrm{~mm}$ mesh and below), the length structures obtained from these scientific campaigns could be substituted for commercial data without great imprecision. In respect of the overall landings, the subsampling ratio can also be estimated fairly reasonably, and indeed independent methods resulted in similar estimates.

Two programs, ANALEN (Chevaillier and Laurec, 1990) and VIT (Lleonart and Salat, 1992), were used for the analyses. These programs perform yield-per-recruit assessments (and virtual population reconstructions) starting from length-structured data. The programs use the pseudo-cohort approach and require equilibrium conditions; they are both flexible and can accommodate different categories of input, but each has its own limitations in the data structure. Besides the yield-per-recruit analysis, ANALEN can calculate short- and long-term variations of production after a modification of the exploitation regimen; VIT also allows a study of the transitional period, and a variable recruitment can be associated in the evolution of the scenarios.

The projections of future production have been studied using ANALEN, applying data from the new set (selectivity study) only. The virtual population vectors are the same as those examined in Bianchini and Ragonese (2001), while the input parameters were derived from Bianchini (1999), and are:

$\mathrm{CL}_{\infty}=70 \mathrm{~mm}(\mathrm{StD} 4.9) ; \mathrm{K}=0.6 / \mathrm{y}(\mathrm{StD} 0.018) ;$ $\mathrm{M}=0.5$; lower bound of last $\mathrm{CL}$ class $=62 \mathrm{~mm}$; $\mathrm{F}_{\text {term }}=0.5 ; \mathrm{a}=0.0013 ; \mathrm{b}=2.642$; reference mesh $=40 \mathrm{~mm}$, stretched; selection factor $=0.88$; selection range $=5.7 ; \mathrm{CL}_{\text {maturity } 50 \%}=40 \mathrm{~mm}$; range of $\mathrm{CL}_{\text {maturity }}$ $=4 \mathrm{~mm}$; price categories $=4$ (for classes of lower weight of 27, 14, 6 and $3 \mathrm{~g}$, respective values are approx. 15, 9, 5 and 3.50 Euro).

The VIT's transition analysis studies the evolution of a population when the mortality vector is modified (e.g. by a change in fishing effort) or the recruitment is not considered constant; in the first case, after a certain number of years, a new equilibrium is reached, and everything reverts to steady-state situation, while of course, in the second type of simulations, the population keeps fluctuating. The VIT's transition analysis is limited to data structured by ageclasses, and the program itself has an option to pro- 
duce age-structured data from length-structured inputs. A complete description of the VIT methodologies and of their theoretical foundations is reported in the application manual by Lleonart and Salat, 1997.

The transitional analyses were performed on both data sets (trawl surveys and selectivity study). The virtual population vectors and the input parameters are again the same, but VIT requires more information, i.e.: maturation, which starts at $26 \mathrm{~mm} \mathrm{CL}$ and is general at $40 \mathrm{~mm} \mathrm{CL}$; a proportion factor, so as to reach a catch of 1050 tons equal to 624 for the selectivity data, while the earlier data set requires a factor of 3350 .

In terms of the recruitment variability, there is not enough information to decide which stockrecruitment model, Beverton and Holt's or Ricker's, should be preferred; therefore, a mere stochastic variability has been applied to the "constant recruitment" situation. In the earlier surveys a variance of 1 has been applied to the log-normal distribution, thus resulting in a mode at 0.354 and a median at 0.707 of the mean, and upper and lower limits of the $95 \%$ confidence interval at 0.138 and 3.616; for the data from the selectivity study a variance of 0.5 has been applied, thus resulting in a mode at 0.544 and a median at 0.816 of the mean, and limits of the confidence interval at 0.234 and 2.844 .

As a general rule, the price-per-unit of weight increases with shrimp size (Fig. 2). The Italian market considers four categories of red shrimp, arranged in the European way from "I" (the best one) to "IV" (small animals, not always over the minimum legal size). The prices vary in a bracket of $\pm 25 \%$ according to demand but the averages considered here are 15, 9, $5,3.50 € / \mathrm{kg}$ respectively for each category, roughly equivalent to $6.50,3.50,2.00,1.50 \mathrm{US} \$ / \mathrm{lb}$.

VIT does not allow for different "price categories", as is the case with the red shrimps. Nevertheless, since the assignment of a given shrimp to a specific "price stanza" is subject to considerable error (manual sorting), the price vector mimics a positive allometric potential curve $(b>3)$. This length-value function, when replacing the length-weight regression, may be used to compute the economic returnper-recruit, in a way similar to the "standard" $\mathrm{Y} / \mathrm{R}$ analysis, with the same input parameters. Considering the distribution of sizes in each price "stanza", value in Euro and carapace length in $\mathrm{mm}$ can be modeled by the regression $€=2.17 \times 10^{-7} \times \mathrm{CL}^{3.708}$.

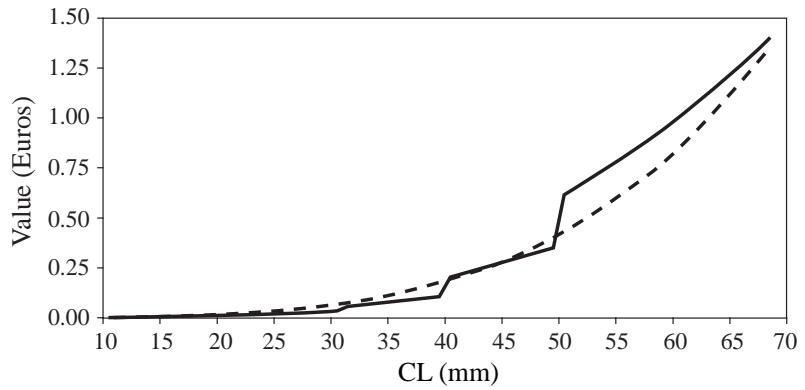

Fig. 2. Approximate individual value of red shrimps, by size (Italian market; value in Euro; size in $\mathrm{mm}$ of CL): solid line $=$ price categories; dashed line $=$ price function.

The selectivity data require a weighing factor of 772 (a multiplier of the sample capture, used to reach a total value for the catch of 13 million Euro), while the earlier surveys require a proportion factor of 1570 .

Besides the standard approach, i.e. the "stanza" prices, the price function has also been used with the ANALEN model.

\section{Results}

\section{Yield scenarios}

The estimates of the variations (\%) in the shortand long-term productions per recruit, varying fishing mortality and/or mesh size, obtained by the ANALEN program from the selectivity study data, are reported in Table 1 and Table 2, respectively. Figures represent the percent variation assuming the present situation as standard ( $\mathrm{F}=100 \%$ of starting $\mathrm{F}$; mesh $=40 \mathrm{~mm}$ stretched).

It is apparent that an increase in the mesh size from $40 \mathrm{~mm}$ to $48 \mathrm{~mm}$, or even to $56 \mathrm{~mm}$, produces only a marginal loss in the short-term, which is rapidly offset by the gain in the long-term. This trend is even more evident when the mesh increase is accompanied by a reduction of the fishing mortality.

\section{Transitional period (earlier surveys)}

The VIT program, using the virtual population reconstruction from the earlier surveys, permits one to examine the transitional behaviour of the fishery, when passing from the old steady-state to the new equilibrium (Fig. 3).

A sudden reduction of the fishing mortality of $15 \%$ (line a) produces in the first year a drop of $10 \%$ 
TABLE 1. Variations in the short-term productions (\%, weight per recruit) of Aristaeomorpha foliacea in different exploitation scenarios, varying fishing mortality and/or mesh size; starting situation (Strait of Sicily) underlined.

\begin{tabular}{lrrrrrrrrrr}
\hline \hline \multicolumn{1}{c}{ Mesh } & \multicolumn{10}{c}{ F multipliers } \\
\hline 64 & 0.50 & 0.60 & 0.70 & 0.80 & 0.90 & 1.00 & 1.10 & 1.20 & 1.30 & 1.40 \\
\hline 56 & -53.47 & -44.17 & -34.86 & -25.56 & -16.25 & -6.95 & 2.36 & 11.67 & 20.97 & 30.28 \\
48 & -51.92 & -42.30 & -32.68 & -23.07 & -13.45 & -3.83 & 5.78 & 15.40 & 25.02 & 34.63 \\
40 & -50.75 & -40.90 & -31.05 & -21.20 & -11.35 & -1.50 & 8.35 & 18.20 & 28.05 & 37.90 \\
32 & -50.00 & -40.00 & -30.00 & -20.00 & -10.00 & 0.00 & 10.00 & 20.00 & 30.00 & 40.00 \\
\hline
\end{tabular}

TABLE 2. Variations in the long-term productions (\%, weight per recruit) of Aristaeomorpha foliacea in different exploitation scenarios, varying fishing mortality and/or mesh size; starting situation (Strait of Sicily) underlined.

\begin{tabular}{lrllrrrrrrr}
\hline \hline \multirow{2}{*}{ Mesh } & \multicolumn{8}{c}{ F multipliers } \\
\hline 64 & 0.50 & 0.60 & 0.70 & 0.80 & 0.90 & 1.00 & 1.10 & 1.20 & 1.30 & 1.40 \\
\hline 56 & 5.16 & 8.37 & 9.98 & 10.59 & 10.57 & 10.15 & 9.48 & 8.66 & 7.74 & 6.78 \\
48 & 3.67 & 6.44 & 7.64 & 7.88 & 7.51 & 6.76 & 5.79 & 4.69 & 3.52 & 2.31 \\
40 & 1.90 & 4.22 & 5.00 & 4.85 & 4.12 & 3.05 & 1.78 & 0.39 & -1.05 & -2.50 \\
32 & 0.39 & 2.35 & 2.80 & 2.34 & 1.33 & 0.00 & -1.51 & -3.12 & -4.76 & -6.41 \\
& -0.46 & 1.29 & 1.56 & 0.94 & -0.22 & -1.70 & -3.34 & -5.07 & -6.82 & -8.57 \\
\hline
\end{tabular}

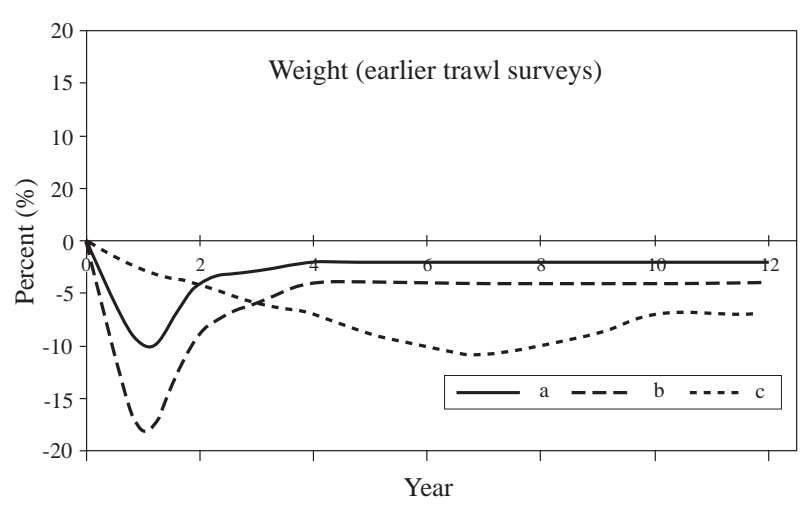

Fig. 3. Transitional status of the Aristaeomorpha foliacea fishery with different management interventions (reduction of the fishing mortality: $a=15 \%$ sudden; $b$ $=25 \%$ sudden; $\mathrm{c}=35 \%$ in 7 years); percent yield (weight per recruit) variations, analysis from 198587 data.

in the yield-per-recruit; in the second year, the yield recovers $6 \%$, and it is stable in the fourth year at $98 \%$ of the initial value. The increase in biomass of the standing stock (SS) is $4 \%$ in the first year, $8 \%$ in the second, and stabilizes in the fourth year at $10 \%$ above the starting value. For the spawning stock biomass (SSB), the respective increases are $5 \%, 11 \%$ and $15 \%$. A sudden reduction of the fishing mortality of $25 \%$ (line b) produces in the first year a drop of $18 \%$ in the yield-per-recruit; in the second year, the yield recovers $10 \%$, and it is stable in the fourth year at $96 \%$ of the initial value. The increase in SS is $7 \%$ in the first year, $17 \%$ in the second, and stabilizes in the fourth year $19 \%$ above the starting value. For the SSB, the respective increases are $9 \%, 20 \%$ and $26 \%$.

A reduction of the fishing mortality of $35 \%$ over 7 years (line c), with a constant annual reduction of $5 \%$, produces a smoother transition: 7 years of small drops in the yield-per-recruit, up to the lowest $89 \%$, and a partial recovery for 3 years, reaching a stable situation at $93 \%$ of the initial value in the $10^{\text {th }}$ year. Every year during the transition there is an increase in SS that levels off at $130 \%$ in 10 years; the SSB is also always increasing, up to $140 \%$ of the starting value.

Applying a stochastic variability to the "constant recruitment" situation, over a period of 15 years, with a sudden drop in the fishing mortality of $15 \%$, the yield-per-recruit is expected to stay between $90 \%$ and $110 \%$ of the starting level $(91 \%$ and $111 \%$ of the new target level), but with ample possible fluctuations (95\% confidence intervals with borders as low as $23 \%$ and as high as $330 \%$ of the starting value). With a 
sudden drop in the fishing mortality of $25 \%$, the yield is expected to stay between $82 \%$ and $102 \%$ of the starting level ( $85 \%$ and $106 \%$ of the new target level), but with ample fluctuations $(95 \%$ confidence intervals with borders as low as $24 \%$ and as high as $269 \%$ of the starting value). With a gradual drop in the fishing mortality of $35 \%$ in 7 years, the yield is expected to stay between $85 \%$ and $96 \%$ of the starting level (92\% and $104 \%$ of the new target level), again with substantial fluctuations $(95 \%$ confidence intervals with borders as low as $23 \%$ and as high as $266 \%$ of the starting value).

\section{Transitional period (selectivity study)}

Again, the virtual population reconstruction from the selectivity study can be used to examine the transitional behaviour of the fishery (Fig. 4).

A sudden reduction of the fishing mortality of $15 \%$ (line a) produces in the first year a drop of $8 \%$ in the yield-per-recruit; in the second year the yield is already $101 \%$ of the starting value, and it is stable in the fourth year at $104 \%$ of the initial value. The increase in SS is 7\% in the first year, $12 \%$ in the second, and stabilizes in the fourth year at $14 \%$ above the starting value. For the SSB, the respective increases are $8 \%, 15 \%$ and $18 \%$. A sudden reduction of the fishing mortality of $25 \%$ (line b) produces in the first year a drop of $14 \%$ in the yield-per-recruit; in the second year, the yield is back to a full $100 \%$, and stabilizes in the fourth year at $106 \%$ of the initial value. The increase in SS is $11 \%$ in the first year, $22 \%$ in the second, and stabilizes in the fourth year $26 \%$ above the starting value. For the SSB, the respective increases are $13 \%, 27 \%$ and $32 \%$.

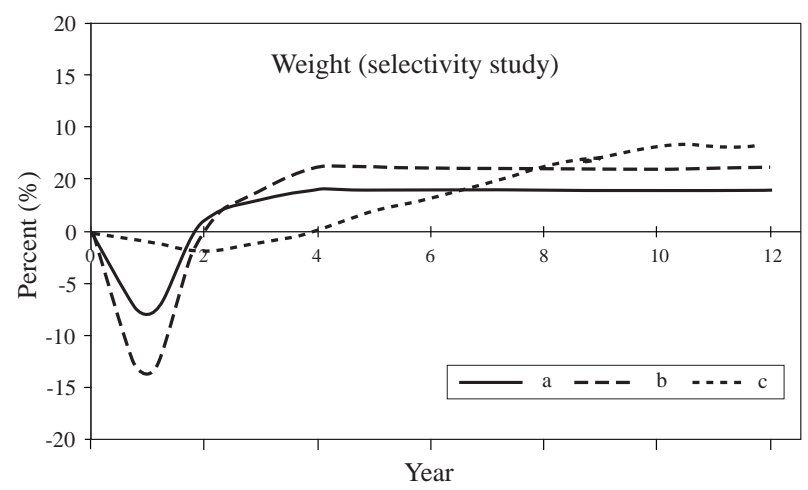

Fig. 4. Transitional status of the Aristaeomorpha foliacea fishery with different management interventions (reduction of the fishing mortality: $a=15 \%$ sudden; $b$ $=25 \%$ sudden; $c=35 \%$ in 7 years); percent yield (weight per recruit) variations, analysis from 1993 data.
A reduction of the fishing mortality of $35 \%$ over 7 years (line c), with a constant annual reduction of $5 \%$, produces of course a smoother transition: 2 years of small drops in the yield-per-recruit, up to the lowest $98 \%$, a partial recovery for another 2 years, increasing up a stable situation of $108 \%$ of the initial value in the tenth year. Every year during the transition there is an increase in SS that levels off at $141 \%$ in 9 years; the SSB is also always increasing, up to $152 \%$ of the starting value.

Considering a stochastic variability in recruitment, over a period of 15 years, with a sudden drop in the fishing mortality of $15 \%$, the yield-per-recruit is expected to stay between $92 \%$ and $112 \%$ of the starting level ( $89 \%$ and $108 \%$ of the new target level), but with ample possible fluctuations (95\% confidence intervals with borders as low as $38 \%$ and as high as $242 \%$ of the starting value). With a sudden drop in the fishing mortality of $25 \%$, the yield is expected to stay between $86 \%$ and $114 \%$ of the starting level $(81 \%$ and $101 \%$ of the new target level), but with ample fluctuations ( $95 \%$ confidence intervals with borders as low as $40 \%$ and as high as $244 \%$ of the starting value). With a gradual drop in the fishing mortality of $35 \%$ in 7 years, the yield is expected to stay between $96 \%$ and $116 \%$ of the starting level $(89 \%$ and $107 \%$ of the new target level), again with substantial fluctuations $(95 \%$ confidence intervals with borders as low as $37 \%$ and as high as $246 \%$ of the starting value).

\section{Economic return scenarios}

The estimates of the economic variations (\%) in the short and long-term productions, varying fishing mortality and/or mesh size, obtained from the selectivity study data, with the classical approach of price "stanzas", are reported in Tables 3 and 4, respectively. It is apparent that an increase in the mesh size from $40 \mathrm{~mm}$ to $48 \mathrm{~mm}$, or even to $56 \mathrm{~mm}$, produces only marginal losses in the short term, which are offset by the gain in the long-term. This trend is even more evident when the mesh increase is accompanied by a reduction of the fishing mortality.

The estimates of the economic variations (\%) in the short- and long-term productions, varying fishing mortality and/or mesh size, obtained from the selectivity study data, with the ad hoc approach of a continuous price function, are reported in Tables 5 and 6 , respectively. Once again an increase in the mesh size from $20 \mathrm{~mm}$ to $24 \mathrm{~mm}$, or even to $28 \mathrm{~mm}$, produces only marginal losses in the short term, which are offset by the gain in the long term. 
TABLE 3. Variations in the economic short-term productions (\%, value per recruit by price category) of Aristaeomorpha foliacea in different exploitation scenarios, varying fishing mortality and/or mesh size; starting situation (Strait of Sicily) underlined.

\begin{tabular}{lrrrrrrrrrr}
\hline \hline \multirow{2}{*}{ Mesh } & 0.50 & 0.60 & 0.70 & 0.80 & 0.90 & 1.00 & 1.10 & 1.20 & 1.30 & 1.40 \\
\hline 64 & -51.63 & -41.96 & -32.29 & -22.61 & -12.94 & -3.27 & 6.41 & 16.08 & 25.75 & 35.42 \\
56 & -50.75 & -40.90 & -31.05 & -21.20 & -11.35 & -1.50 & 8.35 & 18.20 & 28.05 & 37.90 \\
48 & -50.25 & -40.30 & -30.35 & -20.41 & -10.46 & -0.51 & 9.44 & 19.39 & 29.34 & 39.29 \\
40 & -50.00 & -40.00 & -30.00 & -20.00 & -10.00 & 0.00 & 10.00 & 20.00 & 30.00 & 40.00 \\
32 & -49.92 & -39.90 & -29.89 & -19.87 & -9.85 & 0.16 & 10.18 & 20.20 & 30.21 & 40.23 \\
\hline
\end{tabular}

TABLE 4. Variations in the economic long-term productions (\%, value per recruit by price category) of Aristaeomorpha foliacea in different exploitation scenarios, varying fishing mortality and/or mesh size; starting situation (Strait of Sicily) underlined.

\begin{tabular}{lrrrrrrrrrr}
\hline \hline & & \multicolumn{7}{c}{ F multipliers } \\
Mesh & 0.50 & 0.60 & 0.70 & 0.80 & 0.90 & 1.00 & 1.10 & 1.20 & 1.30 & 1.40 \\
\hline 64 & 15.78 & 18.07 & 18.55 & 17.90 & 16.57 & 14.81 & 12.82 & 10.71 & 8.54 & 6.36 \\
56 & 13.14 & 14.80 & 14.69 & 13.51 & 11.70 & 9.51 & 7.12 & 4.64 & 2.14 & -0.34 \\
48 & 10.33 & 11.38 & 10.71 & 9.02 & 6.75 & 4.15 & 1.39 & -1.43 & -4.23 & -6.99 \\
40 & 8.10 & 8.67 & 7.58 & 5.52 & 2.90 & 0.00 & -3.03 & -6.09 & -9.11 & -12.07 \\
32 & 6.91 & 7.24 & 5.93 & 3.67 & 0.88 & -2.18 & -5.35 & -8.53 & -11.66 & -14.71 \\
\hline
\end{tabular}

TABLE 5. Variations in the economic short-term productions (\%, value per recruit by continuous price function) of Aristaeomorpha foliacea in different exploitation scenarios, varying fishing mortality and/or mesh size; starting situation (Strait of Sicily) underlined.

\begin{tabular}{lrrrrrrrrrr}
\hline \hline & & \multicolumn{7}{c}{ F multipliers } \\
Mesh & 0.50 & 0.60 & 0.70 & 0.80 & 0.90 & 1.00 & 1.10 & 1.20 & 1.30 & 1.40 \\
\hline 64 & -52.14 & -42.57 & -32.99 & -23.42 & -13.85 & -4.27 & 5.30 & 14.87 & 24.44 & 34.02 \\
56 & -51.06 & -41.27 & -31.48 & -21.70 & -11.91 & -2.12 & 7.67 & 17.45 & 27.24 & 37.03 \\
48 & -50.38 & -40.46 & -30.54 & -20.61 & -10.69 & -0.76 & 9.16 & 19.08 & 29.01 & 38.93 \\
40 & -50.00 & -40.00 & -30.00 & -20.00 & -10.00 & 0.00 & 10.00 & 20.00 & 30.00 & 40.00 \\
32 & -49.86 & -39.83 & -29.80 & -19.77 & -9.74 & 0.29 & 10.32 & 20.35 & 30.37 & 40.40 \\
\hline
\end{tabular}

TABLE 6. Variations in the economic long-term productions ( $\%$, value per recruit by continuous price function) of Aristaeomorpha foliacea in different exploitation scenarios, varying fishing mortality and/or mesh size; starting situation (Strait of Sicily) underlined.

\begin{tabular}{lrrrrrrrrrr}
\hline \hline & & \multicolumn{7}{c}{ F multipliers } \\
Mesh & 0.50 & 0.60 & 0.70 & 0.80 & 0.90 & 1.00 & 1.10 & 1.20 & 1.30 & 1.40 \\
\hline 64 & 17.14 & 18.60 & 18.40 & 17.23 & 15.52 & 13.54 & 11.44 & 9.30 & 7.20 & 5.15 \\
56 & 14.67 & 15.57 & 14.86 & 13.23 & 11.12 & 8.78 & 6.34 & 3.91 & 1.52 & -0.78 \\
48 & 12.03 & 12.37 & 11.15 & 9.08 & 6.57 & 3.86 & 1.10 & -1.63 & -4.28 & -6.84 \\
40 & 9.89 & 9.80 & 8.20 & 5.79 & 2.98 & 0.00 & -3.00 & -5.96 & -8.81 & -11.55 \\
32 & 8.75 & 8.43 & 6.63 & 4.04 & 1.07 & -2.05 & -5.18 & -8.25 & -11.20 & -14.03 \\
\hline
\end{tabular}


It can be seen that the difference in the two approaches, "stanzas" or continuous function, are minimal, therefore allowing the innovative use of the price regression. In fact, not only are the qualitative aspects the same, but even the quantitative figures are almost identical, with differences in the order of $1 \%$ or less.

\section{Economic transitional period (earlier surveys)}

The VIT program, using the virtual population reconstruction from the earlier surveys, permits the examination of the transitional economic behaviour of the fishery, when passing from the old steady-state to the new equilibrium (Fig. 5).

A sudden reduction of the fishing mortality of $15 \%$ (line a) produces in the first year a drop of $10 \%$ in the economic return-per-recruit; in the second year, the economic return recovers $7 \%$, and it is stable in the fourth year back at the initial economic value. A sudden reduction of the fishing mortality of $25 \%$ (line b) produces in the first year a drop of $17 \%$ in the economic return-per-recruit; in the second year, the economic return recovers $11 \%$, and it is stable in the fourth year at $99 \%$ of the initial economic value. A reduction of the fishing mortality of $35 \%$ over 7 years (line c), with a constant annual reduction of $5 \%$, produces of course a smoother transition: 7 years of small drops in the economic return-per-recruit, up to the lowest $91 \%$, and a partial recovery for three years, reaching a stable situation at $97 \%$ of the initial economic value in the tenth year.

Having applied a stochastic variability in recruitment, over a period of 15 years, with a sudden drop in the fishing mortality of $15 \%$, the economic returnper-recruit is expected to stay between $88 \%$ and $113 \%$ of the starting (and new target) level, but with ample possible fluctuations $(95 \%$ confidence intervals with borders as low as $20 \%$ and as high as $313 \%$ of the starting economic value). With a sudden drop in the fishing mortality of $25 \%$, the economic return is expected to stay between $83 \%$ and $111 \%$ of the starting level $(84 \%$ and $113 \%$ of the new target level), but with ample fluctuations $(95 \%$ confidence intervals with borders as low as $20 \%$ and as high as $309 \%$ of the starting economic value). With a gradual drop in the fishing mortality of $35 \%$ in 7 years, the economic return is expected to stay between $88 \%$ and $99 \%$ of the starting level $(91 \%$ and $102 \%$ of the new target level), again with substantial fluctuations ( $95 \%$ confidence intervals with borders as low as $21 \%$ and as high as $291 \%$ of the starting economic value).

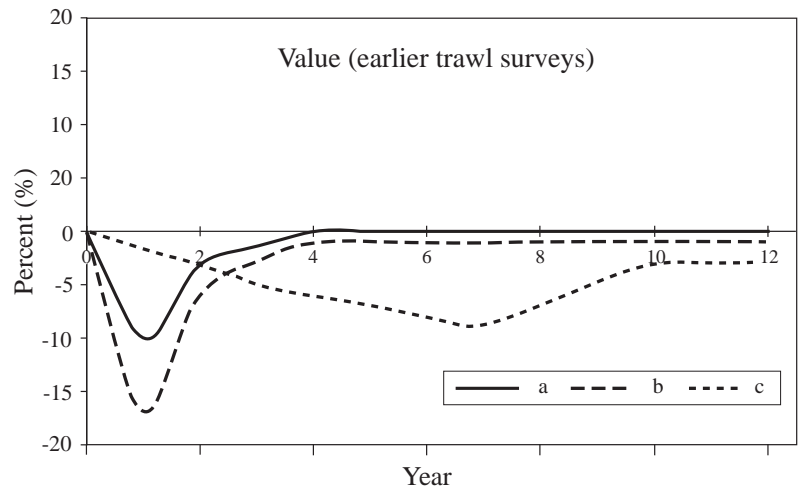

Fig. 5. Transitional economics of the Aristaeomorpha foliace a fishery with different management interventions (reduction of the fishing mortality: $a=15 \%$ sudden; $b=25 \%$ sudden; $c=35 \%$ in 7 years); percent economic return (value per recruit) variations, analysis from 1985-87 data.

\section{Economic transitional period (selectivity study)}

The virtual population reconstruction from the selectivity study also permits an examination of the transitional economic behaviour of the fishery (Fig. 6).

Examining the transitional behaviour of the fishery, a sudden reduction of the fishing mortality of $15 \%$ (line a) produces in the first year a drop of $7 \%$ in the economic return-per-recruit; in the second year, the economic return surpasses the initial value at $103 \%$, and it is stable in the fourth year at $107 \%$. A sudden reduction of the fishing mortality of $25 \%$ (line b) produces in the first year a drop of $13 \%$ in the economic return-per-recruit; in the second year, the economic return again surpasses the initial value at $103 \%$, and it is stable in the fourth year at $111 \%$ of the initial economic value. A reduction of the fishing mortality of $35 \%$ over 7 years (line c), with a constant annual reduction of $5 \%$, produces of course a smoother transition: two years of small drops in the economic return-per-recruit, up to the lowest $97 \%$, and a complete recovery at three years, reaching a stable situation of $115 \%$ of the initial economic value in the tenth year.

With a stochastically variable recruitment, over a period of 15 years, with a sudden drop in the fishing mortality of $15 \%$, the economic return-per-recruit is expected to stay between $92 \%$ and $113 \%$ of the starting level ( $87 \%$ and $108 \%$ of the new target level), but with ample possible fluctuations (95\% confidence intervals with borders as low as $37 \%$ and as high as $248 \%$ of the starting economic value). With a sudden 


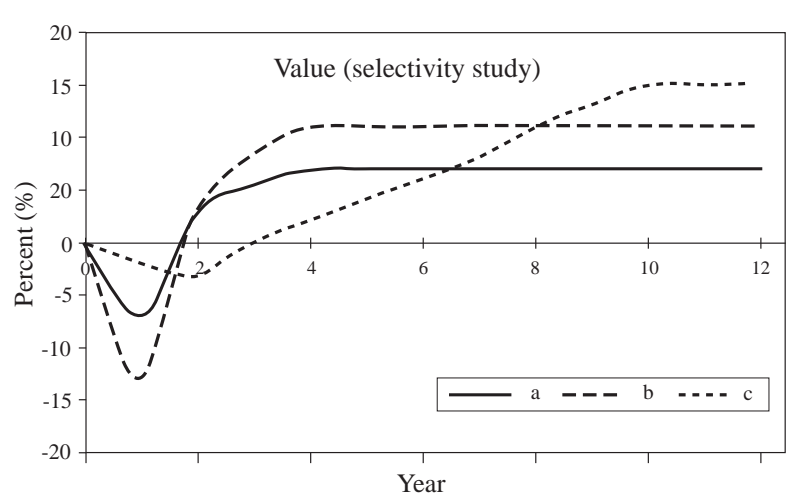

Fig. 6. Transitional economics of the Aristaeomorpha foliacea fishery with different management interventions (reduction of the fishing mortality: $a=15 \%$ sudden; $b=25 \%$ sudden; $c=35 \%$ in 7 years); percent economic return (value per recruit) variations, analysis from 1993 data.

drop in the fishing mortality of $25 \%$, the economic return is expected to stay between $87 \%$ and $114 \%$ of the starting level $(84 \%$ and $113 \%$ of the new target level), but with ample fluctuations $(95 \%$ confidence intervals with borders as low as $41 \%$ and as high as $251 \%$ of the starting economic value). With a gradual drop in the fishing mortality of $35 \%$ in 7 years, the economic return is expected to stay between $93 \%$ and $121 \%$ of the starting level $(91 \%$ and $102 \%$ of the new target level), again with substantial fluctuations (95\% confidence intervals with borders as low as $41 \%$ and as high as $291 \%$ of the starting economic value).

\section{Discussion}

The yield-per-recruit estimates and the virtual population reconstructions have been applied in the population assessment of the companion species Aristeus antennatus (Demestre and Lleonart, 1993; García and Esteban, 1999); these analyses, however, require commercial statistics that are seldom collected in the Strait of Sicily. All these estimates are obviously based on the equilibrium assumption, although the life history of the red shrimp does conform to the theoretical assumptions only loosely. The equilibrium assumptions are an oversimplification of the natural conditions, but they could be supposed at least when dealing with short- and medium-term issues.

In the A. foliacea fishery, as in the case of $A$. antennatus, the shape of all the yield-per-recruit curves suggests a rapid increase of yield-per-recruit for small increments of $F$, and thereafter the curves flatten out, without any evidence of a clear maximum.

\section{Yield scenarios}

Using the ANALEN program on the selectivity study data, translated to the absolute values (Table 7), it is apparent that a reasonable increase in the mesh size (from $40 \mathrm{~mm}$ to $48 \mathrm{~mm}$ ) produces only negligible short-term losses, while a net gain is achieved in the long run. This effect is even more marked when changing to the larger mesh $(56 \mathrm{~mm})$; this is the case of both the catch and of its value.

The different approaches to the economic return, i.e. the classical "price stanzas" and the ad hoc continuous price function, produce similar estimates, therefore allowing the innovative use of the price function in the ANALEN procedure.

The two modalities of analysis, even using the same data sets, produce qualitatively different scenarios, i.e. the level of exploitation appears situated on the right or left side of the maximum yield-perrecruit value, the results have demonstrated that an increase in the mesh size employed to catch red shrimp in the Strait of Sicily is feasible without any appreciable loss in the yield from the fishery. On the contrary, an increment in the capture level could be expected even in the short-term, assuming that the shrimps survive the escapement through the mesh without suffering a higher mortality rate. In fact, similar results have already been observed in the companion species $A$. antennatus in the same area (Ragonese and Bianchini, 1996).

The estimates from the earlier data suggest a situation of slight underfishing. On the contrary, the estimates from the newer set suggest a situation of overfishing, with a yield-per-recruit value near the maximum, the fishing mortality situated on the righthand side of the curve, over the fishing mortality corresponding to the maximum yield-per-recruit, and the standing biomass representing only a small fraction of the virgin stock biomass. A drastic reduction of $\mathrm{F}$ will bring the exploitation to a safer level without consistent changes in the yield; in the meantime, the standing biomass should increase.

\section{Transitional period}

Examining the transitional behaviour of the fishery, when passing from the old steady-state to the new equilibrium, the earlier and the newer data sets produce different results, when examining both the biological yields or the economic returns (Table 8). 
TABLE 7. Long-term economic productions (gross return, in million Euro) of Aristaeomorpha foliacea in different exploitation scenarios, varying fishing mortality and/or mesh size; starting situation (Strait of Sicily) underlined.

\begin{tabular}{lrrrrrr}
\hline \hline & \multicolumn{5}{c}{ F multipliers } \\
Mesh & 0.70 & 0.80 & 0.90 & 1.00 & 1.10 & 1.20 \\
\hline 56 & 14.92 & 14.70 & 14.43 & 14.13 & 13.81 & 13.50 \\
48 & 14.43 & 14.16 & 13.84 & 13.50 & 13.13 & 12.77 \\
40 & 14.05 & 13.74 & 13.37 & 13.00 & 12.60 & 12.21 \\
\hline
\end{tabular}

TABLE 8. Transitional results for Aristaeomorpha foliacea in three scenarios of fishing mortality reduction, with various data sets.

\begin{tabular}{|c|c|c|c|}
\hline F reduction & $15 \%($ sudden $)$ & $25 \%$ (sudden $)$ & $35 \%$ (smooth) \\
\hline \multicolumn{4}{|c|}{ 1985-87 data } \\
\hline$\%$ biological short-term drop & -10 & -18 & $\approx-11$ at year 7 \\
\hline$\%$ biological long-term loss & -2 & -4 & -7 \\
\hline$\%$ long-term standing stock increase & 10 & 19 & 30 \\
\hline$\%$ economic short-term drop & -10 & -17 & $\approx-9$ at year 7 \\
\hline$\%$ economic long-term loss & 0 & -1 & -3 \\
\hline \multicolumn{4}{|c|}{1993 data } \\
\hline$\%$ biological short-term drop & -8 & -14 & $\approx-2$ at year 2 \\
\hline$\%$ biological long-term gain & 4 & 6 & 8 \\
\hline$\%$ long-term standing stock increase & 14 & 26 & 41 \\
\hline$\%$ economic short-term drop & -7 & -13 & $\approx-3$ at year 2 \\
\hline$\%$ economic long-term gain & 7 & 11 & 15 \\
\hline
\end{tabular}

The earlier surveys data show that after the drop that follows the reduction of the fishing mortality, the yield never fully recovers and stabilizes at a lower level after a few years. In percentages, the short-term drop is in the order of two thirds of the fishing mortality reduction, and the long-term loss in the order of about one fourth of the $F$ reduction. Of course, the standing biomass increases steadily, up to a percentage value that is almost two thirds the $F$ reduction.

On the contrary, the selectivity study data show that after the drop that follows the reduction of the fishing mortality, the yield recovers almost immediately and stabilizes at higher level in 3-4 years after the interference has been removed. In percentages, the short-term drop is in the order of half of the fishing mortality reduction, and the long-term gain in the order of about one fourth of the $F$ reduction. In the meantime, the standing biomass increases steadily, up to a percentage value that is almost equal to the $F$ reduction.

From the data of the selectivity study, the economic return suggests a situation of overfishing, with a value away from the maximum on the right side of the curve; a drastic reduction of $F$ (to less than one third) will bring the exploitation to a safer level, say the level of the $F_{0.1}$ strategy, and produce, at the same time, substantial gains over the starting economic return. Conversely, the data from the earlier surveys show that the fishing mortality was almost at its maximum. Even in this case, the pursuit of the safer $F_{0.1}$ strategy would have caused only a modest decrease of the economic return, while the fishing mortality will have been reduced by one third.

During the transitional period, the newer set shows that after the initial drop that follows the 
reduction of the fishing mortality, the yield recovers almost immediately and stabilizes at a higher level in 3-4 years. On the other hand, the earlier data show that after the drop that follows the reduction of the fishing mortality, the yield never fully recovers and stabilizes at a slightly lower level in a few years.

\section{Stochastic recruitment}

There is not enough information to decide which stock-recruitment model, Beverton and Holt's or Ricker's, should be preferred. Therefore, just a stochastic variability of modest intensity has been applied to the "constant recruitment" situation. On average, the yield-per-recruit, over a period of 15 years, stays in acceptable limits that are around $10-15 \%$ of those expected in a steady-state, deterministic situation of a fishing mortality reduction in the range of $15-35 \%$, applied in a sudden or smoothed manner. The same "reasonable" behaviour is shown by the economic return. Nevertheless, ample fluctuations are possible, since the $95 \%$ confidence intervals have borders as low as $40 \%$ or as high as $290 \%$ of the corresponding deterministic realizations. Therefore, the actual outcomes of the fishery, even in a stationary situation, are almost unpredictable (Walters, 1987); a "bad" year following by chance any management intervention, e.g. the increase in the legal mesh size, risks being mis-interpreted by the fishermen as the "ominous effect" of the new regulations.

\section{Conclusions}

Taking as reference the $F_{\max }$ point, the level of exploitation for the red shrimp resources in the Strait of Sicily appears close to the optimal harvest strategy, but very near the maximum or on the right hand of the curve; when considering for example the safer strategy of $F_{0.1}$, it could be implemented with minimal losses, or even with productive gains.

The results of the present study, coupled with more general biological observations on the fisheries in the Strait of Sicily, contribute to strengthen the feeling that, while the shrimp resources are probably not yet exceedingly exploited, some sort of growth overfishing may be present and that the fishing activities are not operating in accordance to an optimal profile; in fact, a similar pattern (growth overfishing and worsened temporal trend) has already been demonstrated, thanks to the discovery of virgin populations, for the Mediterranean deep-water red shrimps (Politou et al., 2000).
The life cycle of red shrimps and the fact that unit value increases markedly with individual size are likely to produce a condition of "economic growth overfishing", i.e. the total weight and total gross value of the shrimp catch is reduced by a premature recruitment to the gear, with the inclusion of too many juveniles of almost no economic value; in fact, the present legal mesh $(40 \mathrm{~mm}$, stretched) is barely selective. Changes in mesh size and type (e.g. squared $v s$ diamond mesh) represent the main management tools aimed at reducing the retention of small and lowerpriced animals and at achieving a separation of the catch from unwanted species. Modification of the mesh type and/or size in the cod-ends appears attractive for the conceptual simplicity and easy enforcement. Therefore, it is advantageous to increase the mesh size in shrimp fisheries, in order to take only sizes with commercial value and to reduce the bycatch. Moreover, from a biological point of view, this should allow a greater number of animals to reach the size at onset of maturity.

In the Sicilian red shrimp fishery, a reduction of the fishing pressure is in theory required in any event:

- if the overexploitation scenario is the right one, in order to bring the fishing mortality back on the left hand of the yield-per-recruit curve;

- in case the situation is one of maximum biological exploitation, in order to pursuit safer strategies such as the $F_{0.1}$, with minimal loss in the yield;

- from the economic point of view, a reduction of the fishing pressure is again required in any event, since it should permit to both pursue safer exploitation strategies and increase the economic returns;

- under any scenario, even a small delay in the age at first capture would be biologically beneficial, without any economic harm, even shortterm.

In conclusion, the adoption of a mesh side of $56 \mathrm{~mm}$ in the codend employed for red shrimp fisheries is strongly recommended because only positive effects, although not drastic, can be expected. The red shrimp fishery will benefit by the proposed management measures directly, through the increased value of the catch, the fact that the exploitation regimen becomes less risky for the resource, the reduced costs of towing a "lighter" gear, the lower labour cost of sorting the commercial catch; and indirectly, through 
the reduction of the by-catch and the improved environmental conditions. In fact, even if escapees from the trawl are dead, their biomass would be left on the oligotrophic deep-water grounds. Nevertheless, the regulation of mesh size could be only a subsidiary device for fisheries management, which should be used together with other management options (for example, a temporary closure in spring).

\section{References}

BIANCHINI, M. L. 1999. The deep-water red shrimp, Aristaeomorpha foliacea, of the Sicilian Channel: biology and exploitation. Univ. of Washington Ph.D. dissertation: $482+17 \mathrm{p}$.

BIANCHINI, M. L., and S. RAGONESE (eds.). 1994. Proceedings of the International Workshop on "Life cycles and fisheries of the deep-water red shrimps Aristaeomorpha foliacea and Aristeus antennatus". N.T.R.-I.T.P.P. Spec. Publ., 3: 87 p.

BIANCHINI, M. L., and S. RAGONESE. 2001. Biological and "economic" virtual population analysis of the red shrimp (Aristaeomorpha foliacea) stock of the Strait of Sicily. Rapp. Comm. Int. Mer Médit., 36: 240.

BIANCHINI, M. L., L. DI STEFANO, and S. RAGONESE. 1998a. Trawl mesh selectivity and body engagement pattern in red shrimp Aristaeomorpha foliacea (Risso, 1827) (Crustacea, Decapoda). J. Nat. Hist., 32(10-11): 14311437.

1998b. Daylight vs. night variations in the red shrimps catches of the Strait of Sicily. Rapp. Comm. Int. Mer Médit., 35(2): 374-375.

CHEVAILLIER, P., and A. LAUREC. 1990. Logiciels pour l'évaluation des stocks de poisson. ANALEN: Logiciel d'analyse des données de capture par classes de taille et de simulation des pêcheries multi-engins avec analyse de sensibilité. FAO Fish. Tech. Doc., 101(suppl. 4): 124 p.

DEMESTRE, M., and J. LLEONART. 1993. The population dynamics of Aristeus antennatus (Decapoda: Dendrobranchiata) in the northwestern Mediterranean. Sci. Mar., 57(2): 183-189.

GARCÍA-RODRIGUEZ, M., and A. ESTEBAN. 2000. A comparison between the biology and the exploitation level of two pink shrimp (Aristeus antennatus) stocks from two different areas in the Spanish Mediterranean. J. C. van Vaupel Klein and F. R. Shram (eds.). In: The
Biodiversity Crisis, Proc. IV Int. Crustacean Congr., 2: 721-732.

LEVI, D. (resp.), S. RAGONESE, M. G. ANDREOLI, G. NORRITO, P. RIZZO, G. B. GIUSTO, S. GANCITANO, G. SINACORI, G. BONO, G. GAROFALO, and L. CANNIZZARO. 1998. Sintesi delle ricerche sulle risorse demersali dello Stretto di Sicilia (Mediterraneo centrale) negli anni 1985-1997 svolte nell'ambito della legge 41/82. Biol. Mar. Medit., 5(3): 130-139.

LLEONART, J., and J. SALAT. 1992. VIT: programa para anàlisis de pesquerìas. Inf. Téc. Sci. Mar., 168-169: $116 \mathrm{p}$.

1997. VIT: software for fisheries analysis - User's manual. FAO Comput. Inf. Ser. (Fish.), 11: 105 p.

POLITOU, C., M. KARKANI, and J. DOKOS. 2000. Distribution of decapods caught during MEDITS surveys in Greek waters. Actes Colloques IFREMER, 26: 196-207.

RAGONESE, S., F. BERTOLINO, and M. L. BIANCHINI. 1997. Biometric relationships of the red shrimp, Aristaeomorpha foliacea Risso 1827, in the Strait of Sicily (Mediterranean Sea). Sci. Mar., 61(3): 367-377.

RAGONESE S. and M.L. BIANCHINI. 1995. Size at sexual maturity in red shrimp females, Aristaeomorpha foliacea, from the Sicilian Channel (Mediterranean Sea). Crustaceana, 68(1): 73-82.

1996. Growth, mortality and yield-per-recruit of the deep-water shrimp Aristeus antennatus (CrustaceaAristeidae) of the Strait of Sicily (Mediterranean Sea). Fish. Res., 26(1): 125-137.

RAGONESE, S., M. L. BIANCHINI, and L. DI STEFANO. 2002. Trawl cod-end selectivity for deep-water red shrimp (Aristaeomorpha foliacea, Risso 1827) in the Strait of Sicily (Mediterranean Sea). Fish. Res., 57(2): 131-144.

RAGONESE, S., M.,L. BIANCHINI, and V. F. GALLUCCI. 1994. Growth and mortality of the red shrimp Aristaeomorpha foliacea in the Sicilian Channel (Mediterranean Sea). Crustaceana, 67(3): 348-361.

RAGONESE, S., M. ZAGRA, L. DI STEFANO, and M. L. BIANCHINI. 2001. Effect of codend mesh size on the performance of the deep-water bottom trawl used in the red shrimp fishery of the Strait of Sicily (Mediterranean Sea). Hydrobiologia, 449: 279-291.

RELINI, G., J. BERTRAND, and A. ZAMBONI (eds.) 1999. Sintesi delle conoscenze sulle risorse da pesca dei fondi del Mediterraneo centrale (Italia e Corsica). Biol. Mar. Medit., 6(suppl. 1), 869 p.

WALTERS C. 1987. Adaptive management of renewable resources. MacMillan Publ. Company, 335 p. 